\title{
Impacto de Mudanças no Emprego no Setor Público sobre o Mercado de Trabalho Local: evidências para as mesorregiões brasileiras de 2003 a 2010 *
}

\author{
Alexandre de Oliveira Lima Loyo \\ Servidor Federal - Secretaria de Acompanhamento Econômico do Ministério da Fazenda \\ Endereço: Esplanada dos Ministérios - Bloco P, Sala 220 - Brasília/DF \\ CEP: 70048-900 - E-mail: alexandreloyo@hotmail.com
}

\section{Moisés de Andrade Resende Filho}

Professor - Faculdade de Economia, Administração, Contabilidade e Gestão de Políticas Públicas (FACE) Universidade de Brasília - Campus Darcy Ribeiro

Endereço: Prédio da FACE Asa Norte - Gabinete A1 87/7 - Bloco A3 - Asa Norte - Brasília/DF

CEP: 70910-900 - E-mail: marf0013@gmail.com

\section{Vander Lucas Mendes}

Professor - Faculdade de Economia, Administração, Contabilidade e Gestão de Políticas Públicas (FACE)

Universidade de Brasília - Campus Darcy Ribeiro

Endereço: Prédio da FACE Asa Norte - Asa Norte - Brasília/DF

CEP: 70910-900 - E-mail: vlucasunb@gmail.com

Recebido: 08/10/2016. Aceite: 06/06/2017.

\section{Resumo}

Estima-se o parâmetro de impacto do aumento no emprego no setor público sobre o emprego no setor privado local nos dois governos Lula (2003 a 2010), considerando o mercado de trabalho formal em 137 mesorregiões e 20 subsetores de atividades econômicas no Brasil. Adaptou-se o método de variável instrumental de Faggio e Overman (2014) a um modelo econométrico de dados em painel que permite ao parâmetro de impacto variar em cada governo Lula. Os resultados mostraram que sob a política fiscal contracionista do primeiro governo Lula o impacto foi eliminador, mas no seu segundo mandato, sob política fiscal expansionista, o impacto foi multiplicador. Ademais, a mudança no emprego no setor público afetou a composição setorial do emprego no curto prazo no Brasil, pois nos setores de bens comercializáveis (indústria) e não comercializáveis (construção e serviços) houve um impacto eliminador no primeiro governo Lula e um impacto multiplicador no segundo governo Lula.

\section{Palavras-Chave}

Mercado de trabalho. Setor público. Dados em painel. Variável instrumental.

\footnotetext{
- Agradecemos aos valiosos comentários e sugestões de dois pareceristas anônimos. O autor Vander Lucas agradece o apoio financeiro da FAPDF. O autor Moisés A. Resende Filho agradece a bolsa de produtividade em pesquisa ao CNPq. Qualquer erro remanescente é de responsabilidade dos autores. A opinião expressa no artigo é exclusivamente dos autores e não reflete uma posição institucional.
} 


\begin{abstract}
We estimate the parameter of the impact of an increase in the public sector employment on private sector employment in the two terms of President Lula (2003 to 2010), taking the formal labor market in 137 mesoregions and 20 subsectors of economic activity in Brazil. We adapt the instrumental variable method of Faggio and Overman (2014) to a panel data econometric model that allows the impact parameter to vary across the two President Lula's terms. The results showed that under the contractionary fiscal policy of the Lula's first term the impact was crowding out, but under the expansionary fiscal policy of the Lula's second term, the impact was multiplier. Moreover, the change in the public employment affected the sectorial composition of employment in Brazil in the short run, as we found crowding out and multiplier effects for the first and second Lula terms in the tradable goods (industry) and non tradable (construction and services) sectors of the Brazilian economy.
\end{abstract}

\title{
Keywords
}

Labor market. Public sector. Panel data. Instrumental variable.

\section{JEL Classification}

H30. J08. C23.

\section{Introdução}

Ao longo das últimas duas décadas, políticas públicas voltadas à geração de emprego, renda e qualificação profissional ${ }^{1}$ promoveram a inserção de milhares de profissionais no mercado de trabalho no Brasil. Dados extraídos da Relação Anual de Informações (RAIS) do Ministério do Trabalho e Previdência Social (MTPS) mostram que nos dois governos do presidente Lula, no período de 2003 a 2010, o número de empregos formais cresceu a uma taxa de 59\%, alcançando 66,7 milhões de empregos em 2010. Ainda nesse período, o subsetor "Administração pública direta e autárquica" foi um dos 26 subsetores de atividade econômica do Instituto Brasileiro de Geografia e Estatística (IBGE) que mais geraram empregos no Brasil. Por exemplo, o subsetor "Administração pública direta e autárquica" respondeu por $14,6 \%$ do emprego formal no Brasil em 2014, tendo sido responsável em estados como Roraima, Amapá e Tocantins por mais que 30\% do emprego formal.

1 Por exemplo, Programas de Geração de Emprego e Renda (Proger), Programa de Fortalecimento da Agricultura Familiar (Pronaf), Programa de Expansão do Emprego e Melhoria da Qualidade de Vida do Trabalhador (Proemprego) e Programa Nacional de Acesso ao Ensino Técnico e Emprego (Pronatec). 
No âmbito internacional, a participação do emprego público no emprego total varia bastante entre países. Nos países nórdicos (Dinamarca, Noruega e Suécia), membros da Organização para a Cooperação e Desenvolvimento Econômico (OCDE), essa participação é de 30\% ou mais, ao passo que nos países membros da OCDE da Ásia e América Latina essa participação é mais baixa. No Japão, por exemplo, a participação é de $8 \%$; no Chile e no México, é de pouco mais de 10\% (OECD 2015).

No Brasil, a contratação de servidores públicos ganhou novos contornos nos últimos anos com a maior atratividade dos planos de cargos e salários das carreiras no setor público, o que elevou o número de interessados (trabalhadores empregados no setor privado, desempregados e jovens recémformados). Por exemplo, de 2003 a 2006, o número de servidores públicos civis federais ativos do Poder Executivo cresceu 7,2\%, chegando a $890 \mathrm{mil}$ servidores. De 2007 a 2010, esse crescimento foi ainda maior, de 9,9\%. ${ }^{2}$ Como base de comparação, nos oito anos (1995-2002) do governo do presidente Fernando Henrique Cardoso, o quantitativo de servidores públicos civis federais ativos do Poder Executivo diminuiu 15,8\%.

O estudo do impacto de variações do emprego público no emprego total tem sido frequente na literatura internacional recente, mas ainda é controverso. Há estudos que defendem o aumento no emprego do setor público enquanto instrumento para reduzir taxas de desemprego elevadas (Stepanyan e Leigh 2015) e induzir crescimento em economias nacionais estagnadas ou em declínio. Estudos nessa linha defendem que a contratação de servidores públicos repercute positivamente de forma direta sobre o mercado de trabalho privado por meio do aumento da demanda agregada e redução do desemprego. Além disso, a criação de empregos no setor público estimula a participação no mercado laboral, na medida em que aumenta as chances de recolocação e as perspectivas salariais dos desempregados (Algan et al. 2002; Stepanyan e Leigh 2015).

Por outro lado, há estudos que defendem que a criação de empregos no setor público impacta negativamente e de forma indireta o mercado de trabalho, notadamente, causando a eliminação de postos de trabalhos no setor privado (Faggio e Overman 2014). Primeiro, se a criação de empregos públicos se dá em atividades com baixo grau de substitutibilidade

2 Esses dados são do Ministério do Planejamento, Desenvolvimento e Gestão (MPDG) e estão disponibilizados em http://www.planejamento.gov.br/secretarias/upload/Arquivos/servidor/ publicacoes/ boletim_estatistico_pessoal/2016/160614_bol237_jan2016_parte_i.pdf . 
como, por exemplo, na polícia, justiça e forças armadas, a destruição de empregos privados é menor do que em atividades com mais alto grau de substitutibilidade como, por exemplo, transporte, educação e saúde (Algan et al. 2002; Senftleben-König 2014). De toda forma, os novos empregos públicos deprimirão a oferta de trabalho se servirem à produção de bens e serviços que estimulam os cidadãos a se manterem fora do mercado de trabalho como, por exemplo, se forem para dar suporte a programas de saúde aos desassistidos e concessão de subsídios à habitação (Algan et al. 2002; Stepanyan e Leigh 2015). Segundo, a criação de novos empregos públicos impacta a despesa e o orçamento do setor público, o que pode levar à elevação da carga tributária, com impactos negativos nos lucros e na capacidade de investimento das empresas, e à necessidade de rearranjos do orçamento com redução de investimentos públicos como, notadamente, em infraestrutura. De todo modo, os impactos negativos na produtividade e demanda agregada das medidas reduzirão a demanda da economia por trabalho (Algan et al. 2002; Boeri e Garibaldi 2006; Máté 2010). Por fim, os maiores ganhos e benefícios dos novos empregados públicos pressionarão os salários no setor privado, o que pode culminar na eliminação de postos de trabalho no setor privado (Holmlund 1997; Máté 2010).

A ausência de consenso sobre o impacto da criação de empregos públicos no emprego privado acaba por fortalecer o cunho político das decisões sobre o emprego público. A quantificação empírica do impacto de variações do emprego público no emprego total constitui uma etapa essencial para tornar essas decisões mais técnicas e menos políticas. Nesse tocante, é importante ainda investigar se o parâmetro do impacto de variações do emprego público no emprego privado e, consequentemente, no emprego total pode ser afetado pelo viés de política fiscal (contracionista ou expansionista) adotado.

O presente estudo tem dois objetivos. O primeiro é estimar o parâmetro de impacto da mudança no emprego público (federal, estadual e municipal) no emprego privado local nas mesorregiões proposta pelo IBGE no período de 2003 a 2010. Como esse parâmetro de impacto pode se alterar em razão do viés de política fiscal, deve-se testar se este permanece igual em todo o período analisado ou se difere entre o primeiro mandato do presidente Lula (2003-2006), caracterizado por uma política fiscal contracionista, e o segundo mandato do presidente Lula (2007-2010), caracterizado por uma política fiscal expansionista. O segundo objetivo é investigar se a mudança no emprego público afeta a composição setorial do emprego no 
curto prazo, como sugerem Faggio e Overman (2014), sendo necessário para tanto estimar o parâmetro de impacto nos setores de não comercializáveis (construção e serviços) e de bens comercializáveis (indústria).

Além desta introdução, o presente artigo possui mais seis seções, tal que: na seção 2, apresenta-se o referencial teórico; na seção 3, a estrutura conceitual, enquanto a seção 4 apresenta os modelos e procedimentos econométricos; a fonte e análise preliminar dos dados é objeto de assunto da seção 5; na seção 6, são apresentados os resultados e discussão e, finalmente, na seção 7 as conclusões.

\section{Revisão de Literatura}

Os estudos que buscam estimar o impacto do emprego público sobre o mercado de trabalho local podem ser classificados em dois grupos: os de caráter transnacional, que apresentam e analisam dados de um número grande de países, e os de caráter nacional, que fazem o mesmo, mas para um único país.

No grupo de estudos de caráter transnacional, Edin e Holmlund (1997), com dados de 22 países da OCDE no período de 1968 a 1990, verificaram que o crescimento do emprego público diminui a taxa de desemprego no curto prazo, mas não apresenta efeito significativo no longo prazo. Boeri et al. (1999) estudaram a relação entre as taxas de emprego não agrícola e de servidores públicos em 19 países industrializados da OCDE entre 1982 e 1999, e encontraram que para cada 10 empregos públicos gerados, há a eliminação de três postos de trabalho privados. Algan et al. (2002) verificaram que o emprego público é um fator importante de influência no desempenho dos mercados de trabalho em uma amostra de 17 países membros da OCDE no período de 1960 a 2000, pois estimaram que a criação de um emprego público eliminava, em média, 1,5 postos de trabalho privados. No entanto, esclarecem que a extensão do efeito "crowding out" do emprego público é maior nos países com maior grau de substitutibilidade da produção pública pela produção privada e nos países em que o setor público paga maiores rendimentos que o setor privado. Stepanyan e Leigh (2015), em estudo empírico baseado em uma amostra de 24 países de renda média elevada, entre eles o Brasil, no período de 1995 a 2011, 
não encontraram evidências de que a geração de empregos públicos reduz a taxa de desemprego a médio e longo prazo, pois estimaram que para cada 100 empregos públicos criados, eliminam-se 70 postos de trabalho privados. Stepanyan e Leigh (2015) também abordam a questão do grau de substitutibilidade entre a produção pública e a produção privada e dos maiores rendimentos pagos pelo setor público, enfatizando a necessidade de reformas para reduzir as rendas e o tamanho do setor público.

Embora os estudos de caráter transnacional possam abranger países com diferentes estruturas produtivas e políticos-institucionais, os resultados encontrados indicam que o emprego público elimina empregos no mercado de trabalho privado. Não obstante, a magnitude desse efeito varie substancialmente entre os estudos.

No grupo de trabalhos de caráter nacional, destacam-se os de Faggio e Overman (2014), Senftleben-König (2014) e Jofre-Monseny et al. (2014), os quais utilizam variáveis instrumentais fundamentadas no método estrutural-diferencial (shift-share) para superar o problema de endogeneidade das estimações tradicionais em painel, semelhante às abordagens desenvolvidas por Card (2007) e Moretti (2010). Faggio e Overman (2014) analisam o impacto do emprego público sobre o emprego do setor privado no Reino Unido, nos períodos de 2003 a 2007 (curto prazo) e 1999 a 2007 (longo prazo), e encontram que o emprego público interfere na composição setorial do setor privado no curto prazo. Especificamente, cada posto de trabalho adicional do setor público cria 0,5 postos de trabalho no setor de não comercializáveis, enquanto que elimina 0,4 postos de trabalho no setor de bens comercializáveis. Quando se considera o período mais longo, não é encontrado nenhum efeito multiplicador no setor de bens não comercializáveis, mas verifica-se a exclusão no setor de bens comercializáveis de 0,8 postos de trabalho e no setor privado total de cerca de um posto de trabalho. Senftleben-König (2014) constatou as mudanças no emprego do setor privado e nos ganhos em todos os mercados de trabalho locais da Alemanha em função de mudanças no emprego público. No interstício de 2003 a 2007, os resultados indicam que 100 postos de trabalho no setor público eliminam 74 postos de trabalho no setor privado. Além disso, encontrou evidências de que o crescimento do emprego público exerce uma pressão crescente sobre os salários locais do setor privado. Nesse sentido, explica que a eliminação de postos de trabalho concentra-se principalmente no setor de bens comercializáveis, no qual os aumentos salariais deterioram a competitividade das indústrias locais. Em oposição, o emprego no setor de não comercializáveis é relativamente pouco afetado, uma vez que 
são compensados pelo crescimento da demanda local. Jofre-Monseny et al. (2014) estimam o efeito do aumento do emprego local no setor público na Espanha sobre o emprego privado local, no período de 1980 a 2001. Os autores mostraram que, no longo prazo, o aumento no emprego público provocou um efeito multiplicador positivo no setor de não comercializáveis, no entanto, provocou um movimento contrário no setor de comercializáveis.

Apesar do número ainda pequeno de trabalhos de caráter nacional, verifica-se que nos estudos realizados para o Reino Unido, Alemanha e Espanha, os resultados estão em linha com a estrutura conceitual, com o setor de comercializáveis concentrando a eliminação das vagas de trabalho. A vantagem dos estudos de caráter nacional é que possibilitam examinar como as particularidades de cada país, principalmente no que tange à elasticidade da oferta de trabalho, impactam na diferença de magnitude do efeito do emprego público no mercado de trabalho privado.

A mensuração de multiplicadores locais entre os setores privados de comercializáveis e de não comercializáveis com a utilização do método diferencial-estrutural (shift-share) foi objeto de estudo no âmbito tanto internacional quanto nacional. Nesses estudos, buscava-se medir unicamente a influência da criação de um novo posto de trabalho no setor privado de comercializáveis na geração de novos postos de trabalho no setor privado de não comercializáveis.

Moretti (2010), Blasio e Menon (2011), Moretti e Thulin (2012) e Dyrstad (2014) estimaram multiplicadores locais respectivamente para os Estados Unidos, Itália e Suécia e Noruega. A rigidez do mercado de trabalho, a baixa variabilidade dos salários, os obstáculos à mobilidade da mão de obra e as diferenças nas políticas econômicas nacionais, foram as principais razões levantadas para justificar as diferenças nas magnitudes das estimativas obtidas para os multiplicadores. No Brasil, Macedo e Monasterio (2014) estimaram o multiplicador de longo prazo do emprego industrial para as mesorregiões brasileiras, no período de 2000-2010, para os setores de comercializáveis (indústria de transformação: alta e baixa tecnologia) e não comercializáveis (serviços). A despeito das estimativas dos multiplicadores locais do emprego no Brasil terem sido altas quando comparadas às obtidas em estudos para os Estados Unidos, Itália e Suécia e Noruega, Macedo e Monasterio (2014) ponderam que estão em linha com esses. O Quadro 1 apresenta um resumo das estimativas dos multiplicadores locais obtidas nos estudos supracitados. 
Quadro 1 - Magnitudes dos multiplicadores locais do emprego no setor de comercializáveis no setor de não comercializáveis

\begin{tabular}{|l|l|c|c|}
\hline \multicolumn{1}{|c|}{ Autor(es) } & \multicolumn{1}{c|}{ País } & eríodo & Multiplicador \\
\hline Moretti (2010) & Estados Unidos & $1980-2000$ & 1,59 \\
\hline Blasio e Menon (2011) & Itália & $1991-2001$ & 0,38 \\
\hline Moretti e Thulin (2012) & Suécia (sem Estocolmo) & $1995-2007$ & 0,48 \\
\cline { 2 - 4 } & Suécia (com Estocolmo) & $1995-2007$ & 3,85 \\
\hline \multirow{2}{*}{ Dyrstad (2014) } & Noruega (sem Oslo) & $1996-2010$ & 0,75 \\
\cline { 2 - 4 } & Noruega (com Oslo) & $1996-2010$ & 2,75 \\
\hline \multirow{2}{*}{ Macedo e Monasterio (2014) } & Brasil (sem São Paulo) & $2000-2010$ & 3,98 \\
\cline { 2 - 4 } & Brasil (com São Paulo) & $2000-2010$ & 6,58 \\
\hline
\end{tabular}

Fonte: Adaptado de Macedo e Monasterio (2014).

\section{Modelo Conceitual}

O modelo conceitual do presente trabalho, a ser apresentado nessa seção, baseia-se em Faggio e Overman (2014) que, com base em Moretti (2010), desenvolveram um modelo conceitual que permitiu incluir o setor público na análise da mudança no emprego privado devido à mudança no emprego público. Para tanto, Faggio e Overman (2014) consideram uma economia fechada, em concorrência perfeita e espacialmente dispersa em unidades geográficas. Essa economia utiliza trabalho para produzir bens comercializáveis com preços determinados em nível nacional e, assim, exógenos às unidades geográficas, bens não comercializáveis com preços determinados em nível local e bens públicos não comercializáveis financiados por tributos. Não há barreiras à migração (mobilidade) da mão de obra entre as unidades geográficas, os salários são localmente determinados nos setores comercializáveis e não comercializáveis, mas o salário do setor público é determinado em nível nacional. Admite-se ainda que haja um diferencial salarial positivo do setor público para o setor-privado, consistente com evidências empíricas para o Brasil (Barbosa e Barbosa Filho, 2012 e Souza e Medeiros, 2013). A função de oferta de mão de obra local é positivamente inclinada e sua inclinação depende das preferências locais por trabalho, da mobilidade da mão de obra entre as unidades geográficas e da oferta de habitação local. Quanto mais rápida é a migração de trabalhadores em resposta a diferenças de salários entre unidades geográficas e a resposta da oferta de habitação local, mais elástica será a oferta de mão de obra local. 
Um choque permanente de elevação na produção local de bem público tem como efeito direto o aumento no emprego na localidade com consequente elevação da renda local (efeito renda) e aumento na demanda local por não comercializáveis (saúde, educação, serviços postais,...), os quais podem ser também produzidos pelo setor público local (efeito substituição). Se o efeito renda domina o efeito substituição, há incremento líquido no emprego na unidade geográfica, caso contrário, há redução no emprego local. Portanto, o impacto (multiplicador ou eliminador) do aumento do emprego público sobre o emprego local é uma questão a ser empiricamente investigada.

O aumento da renda local ou demanda intermediária do setor público terá efeito nulo na demanda agregada do setor de bens comercializáveis, pois esta é, por hipótese, determinada em nível nacional e, assim, a demanda local não consegue afetá-la. Portanto, aumentos de salários, do custo de habitação e do preço de bens e serviços não comercializáveis na unidade geográfica podem somente elevar os custos de produção local, o que deve reduzir a competitividade do setor local de bens comercializáveis e, consequentemente, eliminar empregos nesse setor localmente. Sendo assim, espera-se que o efeito líquido do aumento do emprego público sobre o emprego no setor de comercializáveis seja eliminador e, com isso, altere a estrutura do emprego local com o setor de bens e serviços comercializáveis perdendo participação, o setor público ganhando participação e o setor de não comercializáveis podendo ganhar ou perder participação.

\section{Modelos e Procedimentos Econométricos}

O modelo conceitual de Faggio e Overman (2014) limita-se a indicar um sinal ambíguo do parâmetro de impacto da mudança no emprego público sobre o emprego privado local. No entanto, diante da inflexão na política fiscal do primeiro para o segundo governo do presidente Lula, optou-se por adotar a especificação do modelo econométrico (1), a qual permite testar a estabilidade do parâmetro de impacto no período 2003 a 2010. O modelo conceitual de Faggio e Overman (2014) indica ainda que o aumento da participação do emprego público pode alterar a composição setorial do emprego na economia com a perda de participação do setor de comercializáveis devido ao efeito eliminador, mas podendo ganhar ou perder participação 
com o setor de não comercializáveis. Sendo assim, utiliza-se a especificação do modelo (1) para também estimar o parâmetro de impacto nos setores de não comercializáveis (construção e serviços) e de bens comercializáveis (indústria) o modelo econométrico (1).

$$
\left(\frac{\mathrm{R}_{\mathrm{if}}-\mathrm{R}_{\mathrm{is}}}{\mathrm{E}_{\mathrm{is}}}\right)_{\mathrm{p}}=\alpha_{\mathrm{i}}+\alpha_{\mathrm{p}}+\beta_{1}\left(\frac{\mathrm{B}_{\mathrm{if}}-\mathrm{B}_{\text {is }}}{\mathrm{E}_{\mathrm{is}}}\right)_{\mathrm{p}}+\beta_{2}\left(\tau_{\mathrm{p}} \times\left(\frac{\mathrm{B}_{\mathrm{if}}-\mathrm{B}_{\text {is }}}{\mathrm{E}_{\mathrm{is}}}\right)_{\mathrm{p}}\right)+\gamma^{\prime} \mathrm{x}_{\mathrm{ip}}+\varepsilon_{\text {ip }}
$$

em que $\left(\frac{R_{i f}-R_{i s}}{E_{i s}}\right)_{p}$ é a mudança no emprego do setor privado na unidade geográfica i, entre o final f e início s do período $\mathrm{p}$, normalizada pelo emprego total inicial; $\alpha_{i}$ é o efeito fixo não observável e invariante no tempo da unidade geográfica i; no caso do modelo efeitos aleatórios, $\alpha_{\mathrm{i}}$ é estocástico e passa a compor o erro do modelo (Baltagi 2005; Wooldridge 2002); $\alpha_{p}$ é o efeito fixo de tempo; $\left(\frac{B_{i f}-B_{i s}}{E_{i s}}\right)_{p}$ é a mudança no emprego do setor público na unidade geográfica i, entre o final $\mathrm{f}$ e início s do período $p$, normalizada pelo emprego total inicial; $\tau_{\mathrm{p}} \times\left(\frac{\mathrm{B}_{\mathrm{if}}-\mathrm{B}_{\mathrm{is}}}{\mathrm{E}_{\mathrm{is}}}\right)_{\mathrm{p}}$ é uma variável de interação; $\beta_{1}$ é o impacto de variações no emprego público no emprego no mercado de trabalho privado local em $\mathrm{p}=1$, tal que se $\beta_{1}>0(<0)$, é porque há um efeito multiplicador (eliminador) no setor privado decorrente da geração de emprego público em $\mathrm{p}=1 ;\left(\beta_{1}+\beta_{2}\right)$ é o impacto de variações no emprego público no emprego no mercado de trabalho privado local em $\mathrm{p}=2$, tal que se $\left(\beta_{1}+\beta_{2}\right)>0(<0)$ é porque há um efeito multiplicador (eliminador) no setor privado decorrente da geração de emprego público em $\mathrm{p}=2$; $\gamma$ é o vetor de coeficientes das variáveis controle em $\mathrm{X}_{\mathrm{ip}} ; \mathrm{X}_{\mathrm{ip}}$ é um vetor de variáveis controle que afetam o emprego privado na unidade geográfica i no período p; e $\varepsilon_{\text {ip }}$ é o termo de erro aleatório.

Os trabalhos que utilizam modelos econométricos em linha com a especificação na Equação (1), notadamente Faggio e Overman (2014), utilizam como variáveis independentes: log da população inicial, níveis de escolaridade, taxa de desemprego e dummies de região, setor urbano e rural. No presente trabalho, utilizaram-se as variáveis log da população inicial, níveis de escolaridade, variação do Produto Interno Bruto (PIB) e os efeitos fixos de mesorregião eliminam a necessidade de uso de dummies de 
região e setor urbano e rural. Contudo, a variável taxa de desemprego não foi utilizada porque não há dados para esta nas 137 mesorregiões. Assim, a discussão a seguir reconhece a endogeneidade da variável mudança no emprego no setor público devido à omissão da variável taxa de desemprego e erros de medida e propõe superar o problema por meio da estimação do modelo (1) pelo método de variável instrumental.

Faggio e Overman $(2014)^{3}$ reconhecem que a variável mudança no emprego público no modelo (1) é provavelmente endógena, uma vez que os choques aleatórios na mudança no emprego privado devem se correlacionar à mudança no emprego público. Isso porque choques aleatórios negativos (positivos) no emprego do setor privado podem induzir o governo local a aumentar (eliminar) empregos no setor público, estabelecendo uma correlação negativa da mudança no emprego público e choques aleatórios no emprego privado (endogeneidade). Com isso, as estimativas por Mínimos Quadrados Ordinários (MQO) dos coeficientes do modelo econométrico (1) seriam viesadas e inconsistentes para baixo. Por outro lado, se a relação do emprego público e privado é de complementaridade e não se substituição como antes, choques aleatórios negativos (positivos) no emprego privado levariam o governo local a eliminar (aumentar) empregos públicos, estabelecendo uma correlação positiva da mudança no emprego público e choques aleatórios no emprego privado (endogeneidade). Nesse cenário, as estimativas MQO dos coeficientes do modelo econométrico (1) seriam viesadas e inconsistentes para cima (Faggio e Overman 2014).

Para contornar o problema de endogeneidade da variável mudança no emprego do setor público no modelo (1), faz-se necessário utilizar técnicas de estimação baseadas em variáveis instrumentais. ${ }^{4}$ Nesse sentido, o presente estudo segue o procedimento proposto por Faggio e Overman (2014), que consiste em utilizar a variável instrumental definida segundo a Equação (2):

$$
\left(\frac{\mathrm{B}_{\text {is }}}{\mathrm{E}_{\mathrm{is}}} \times \frac{\mathrm{B}_{-\mathrm{i}, \mathrm{f}}^{\text {Brasil }}-\mathrm{B}_{-\mathrm{i}, \mathrm{s}}^{\text {Brasil }}}{\mathrm{B}_{-\mathrm{i}, \mathrm{s}}^{\text {Brasil }}}\right)_{\mathrm{p}}
$$

em que $B_{\text {is }} / E_{\text {is }}$ é a participação do emprego público no emprego total em i no período inicial s e $\left(\mathrm{B}_{-\mathrm{i}, \mathrm{f}}^{\text {Brail }}-\mathrm{B}_{-\mathrm{i}, \mathrm{s}}^{\text {Brait }}\right) / \mathrm{B}_{-\mathrm{i}, \mathrm{s}}^{\text {Brasil }}$ é a taxa de crescimento no emprego do setor público no restante do país, pois exclui a unidade

3 Também abordado nas pesquisas por Card (2007) e Moretti (2010).

4 Uma variável instrumental (VI) é uma variável que deve ser correlacionada com a variável explicativa potencialmente endógena, ou seja, deve ser relevante, mas não correlacionada com o termo de erro do modelo de regressão, ou seja, deve ser exógena (Gujarati 2004). 
geográfica i (por isso o subscrito $-\mathrm{i}$ ), entre o final $\mathrm{f}$ e início s do período p, normalizada pelo emprego inicial do setor público no restante do país. A variável instrumental gerada por meio da Equação (2) utiliza a taxa de crescimento do emprego público no restante do país, que é correlacionada com a mudança no emprego público em i, mas não é correlacionada com choques e erros de medida na variável mudança no emprego privado na unidade geográfica i. A razão $B_{\text {is }} / E_{\text {is }}$ na Equação (2) faz com que uma mudança no emprego do setor público no restante do país afete a unidade geográfica i de acordo com a participação do emprego público no emprego total nesta no período inicial s. Por exemplo, no caso de uma taxa positiva de crescimento no emprego público no restante do país, quanto maior é a participação inicial do emprego público no emprego total na unidade geográfica i, maior é o aumento de postos de trabalho no setor público de i (Senftleben-König 2014). Em suma, a variável gerada com a Equação (2) é correlacionada com a mudança no emprego público em i e exógena, podendo, portanto, ser considerada um instrumento da variável endógena no modelo (1).

A variável instrumental na Equação (2) foi construída com base no método shift-share, em linha com procedimentos de Card (2007), Moretti (2010) e Moretti e Thullin (2012). O método shift-share é uma das técnicas mais difundidas de análise regional para examinar as diferenças observadas no crescimento econômico de distintas áreas geográficas (países, regiões, municípios). Foi originalmente formulada por Dunn (1960), como um método de determinação dos componentes que explicam as diferenças nas magnitudes econômicas, inicialmente com foco no emprego, mas já foi submetida a inúmeras revisões e extensões nas últimas décadas. A contribuição essencial dessa técnica deve-se a sua capacidade para quantificar o viés geográfico na evolução da economia (Mayor Fernández et al. 2005).

Basicamente, a análise shift-share decompõe a variação absoluta, verificada para uma determinada variável econômica (emprego, renda, produção, entre outras) em três componentes essenciais que tentam explicar a disparidade verificada entre a variação regional e o crescimento nacional, são eles: componente nacional; componente estrutural (também conhecido como efeito de composição); e componente regional (ou efeito de competitividade). Assim, pode-se dar uma descrição total da mudança econômica que é atribuível a cada um desses componentes (Dinc 2002; Nunes e Barros 2012). 
A utilização do método shift-share para a construção de variáveis instrumentais foi inicialmente introduzida nas pesquisas de Bartik (1991) e Blanchard e Katz (1992) (Blasio e Menon 2011). Desde então, essa mesma abordagem foi utilizada em vários trabalhos, destacando-se as pesquisas de Moretti (2010), Blasio e Menon (2011), Moretti e Thulin (2012), Faggio e Overman (2014) e Senftleben-König (2014).

\section{Fonte e Análise dos Dados}

A principal fonte de dados utilizada na presente pesquisa foi a Relação Anual de Informações Sociais (RAIS $)^{5}$ divulgada pelo Ministério do Trabalho e Previdência Social (MTPS). A RAIS é um registro administrativo de periodicidade anual e de abrangência nacional do mercado de trabalho formal brasileiro (CLT e Estatutário). Criado com a finalidade de suprir as necessidades de controle, de estatísticas e de informações às entidades governamentais da área social, esse registro apresenta desagregação do estoque de trabalhadores até em nível municipal, de classe de atividade econômica (CNAE/IBGE) ${ }^{6}$ e de ocupações (CBO/MTPS). ${ }^{7}$

Utilizaram-se os vínculos ativos de trabalho referentes aos anos de 2003, 2006, 2007 e 2010, excluindo-se dessas bases de dados as pessoas que trabalhavam $44 \mathrm{~h}$ por semana e possuíam renda menor que um salário mínimo (R\$240) em 2003, ( $\$$ \$350) em 2006, ( $\mathrm{R} \$ 380)$ em 2007 e (R\$510) em 2010, uma vez que a legislação trabalhista brasileira não permite essa situação. Foram excluídos também os trabalhadores que estavam com vínculo inativo de trabalho nos anos considerados, os com idade menor de 14 e maior de 70 anos de idade, assim como observações com códigos não identificados para as variáveis utilizadas na pesquisa. Esses dados anuais foram agregados em 137 mesorregiões e nos 26 subsetores de atividade econômica do Quadro 2 conforme a classificação utilizada pelo IBGE. ${ }^{8}$ A divisão das mesorregiões brasileiras está detalhada na Tabela Al do Anexo A e segue a divisão regional proposta pelo IBGE, que identifica áreas individualizadas em cada uma das unidades federadas com base em

\footnotetext{
Instituída pelo Decreto n 76.900 de 23 de dezembro de 1975.

6 Classificação Nacional de Atividade Econômica - CNAE/IBGE.

Classificação Brasileira de Ocupações - CBO/MTPS.

8 Foram definidos 25 subsetores e um último subsetor englobando todos aqueles cujas atividades econômicas não se enquadrarem em nenhuma definição dos primeiros 25 subsetores.
} 
três dimensões: o processo social como determinante, o quadro natural como condicionante e a rede de comunicação e de lugares como elemento da articulação espacial.

\section{Quadro 2 - Subsetores de atividades econômicas}

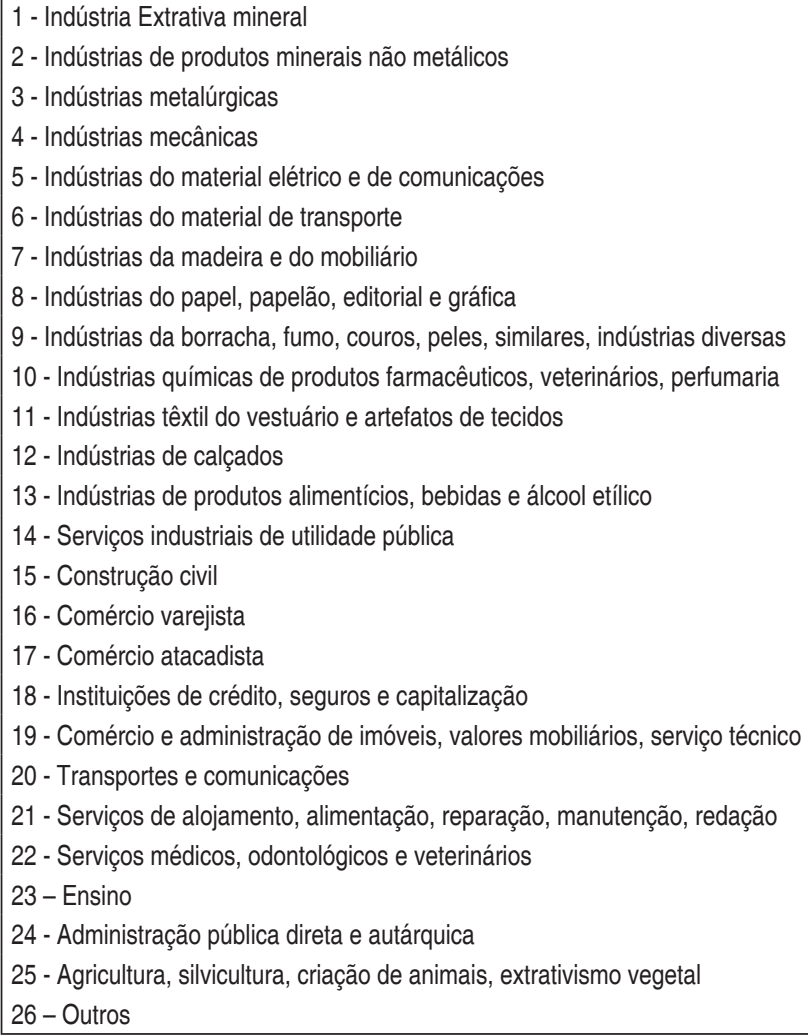

Fonte: IBGE.

Em linha com Faggio e Overman (2014), foram desconsiderados cinco subsetores, quais sejam: agricultura; indústria extrativa mineral; serviços de utilidade pública; transporte e comunicações; e outros. As exclusões dos subsetores agricultura e indústria extrativa mineral devem-se ao fato de serem fortemente baseados em recursos naturais, o que os tornam peculiares e, assim, fora do foco do presente estudo. Os subsetores serviços de utilidade pública e transporte e comunicações foram excluídos porque é provável que alguma parcela de emprego nesses setores seja pública e não 
privada, além de serem relacionados ao fornecimento de bens públicos e, assim, sob regulamentação. Já o subsetor "outros" foi excluído por não ter sido encontrado qualquer registro de vínculo empregatício para os anos analisados.

O Quadro 3 apresenta o percentual dos dados da RAIS remanescentes nos anos utilizados nesta pesquisa, após serem eliminadas observações conforme os critérios descritos anteriormente.

Quadro 3 - Número total de observações, antes e depois do tratamento dos dados (em milhares)

\begin{tabular}{|l|c|c|c|c|}
\hline Observações & RAIS 2003 & RAIS 2006 & RAIS 2007 & RAIS 2010 \\
\hline Dados originais & 41969,2 & 50701,0 & 54649,1 & 66747,3 \\
\hline Dados finais & 25189,9 & 29580,4 & 32257,1 & 37923,9 \\
\hline Participação final (\%) & $60 \%$ & $58,3 \%$ & $59 \%$ & $56,8 \%$ \\
\hline
\end{tabular}

Fonte: Elaboração própria com base nos dados da RAIS/MTPS.

O agrupamento entre comercializáveis (indústria) e não comercializáveis (serviços e construção civil) para os vinte subsetores seguiu a divisão proposta por Marconi e Rocha (2011) ${ }^{9}$ e também utilizada no trabalho de Macedo e Monasterio (2014). Assim, agrupou-se no setor comercializáveis doze subsetores, quais sejam: indústria de produtos minerais não metálicos, indústria metalúrgica; indústria mecânica; material elétrico e comunicações; material de transporte; madeira e mobiliário; papel e gráfica; borracha, fumo e couros; indústria química; indústria têxtil; indústria de calçados; e indústria de alimentos e bebidas. No setor não comercializáveis foram agrupados oito subsetores, quais sejam: construção civil; comércio varejista; comércio atacadista; instituições financeiras; comércio e administração de imóveis; alojamento e manutenção; médicos, odontológicos e veterinários; e ensino. Finalmente, no subsetor "administração pública" estão agrupadas dez descrições de atividades econômicas, quais sejam: Administração pública em geral; Regulação das atividades sociais e culturais; Regulação das atividades econômicas; Atividade de apoio à administração pública; Relações exteriores; Defesa; Justiça; Segurança e ordem pública; Defesa civil; e Seguridade social.

9 Com adaptações, uma vez que os autores não trabalharam com os subsetores de atividade econômica do IBGE. 
Após a agregação dos subsetores em setores comercializáveis, não comercializáveis e setor público (administração pública), fez-se uma triagem dos indivíduos empregados por tipo de vínculo empregatício. No setor "administração pública", nos quatro anos analisados, em média, 90,4\% dos vínculos empregatícios eram classificados como estatutário. ${ }^{10}$ Nos setores comercializáveis e não comercializáveis, 95\% dos vínculos empregatícios encontrados eram de trabalhador urbano vinculado a empregador pessoa jurídica por contrato de trabalho regido pela Consolidação das Leis do Trabalho (CLT) por prazo indeterminado, sendo que apenas $1 \%$ da soma dos vínculos nos dois setores era de vínculos empregatícios do tipo estatutário. Vale lembrar que os empregos formais, tanto regidos pela CLT quanto pelo regime estatutário, são considerados de maior qualidade, pois trabalhadores nesses regimes têm amparo legal.

Ao se observar a participação dos subsetores de atividade econômica que compõem a base de dados em âmbito nacional no Quadro 4, verifica-se que no setor comercializáveis as indústrias de alimentos e bebidas e têxtil são as maiores empregadoras, contribuindo, em média, com 6,7\% dos empregos formais do Brasil. No setor de não comercializáveis, os "serviços" apresentam a maior participação no emprego total nos quatro anos escolhidos, com participação média de 56\%. Destaque para os subsetores de comércio varejista, comércio e administração de imóveis e alojamento e manutenção, que juntos respondiam com 38\% dos empregos nos quatro anos observados. Em relação ao subsetor administração pública, mesmo tendo perdido participação ao longo do período, permaneceu sempre como o maior empregador nacional com mais de $20 \%$ de participação no emprego total.

${ }^{10}$ Entende-se por estatutário: a) Servidor regido pelo Regime Jurídico Único (federal, estadual e municipal) e militar, vinculado a Regime Próprio de Previdência; b) Servidor regido pelo Regime Jurídico Único (federal, estadual e municipal) e militar, vinculado ao Regime Geral de Previdência Social; e c) Servidor público não efetivo (demissível ad nutum ou admitido por meio de legislação especial, não regido pela CLT). 
Quadro 4 - Empregos por subsetor de atividade econômica nos anos 2003, 2006, 2007 e 2010

\begin{tabular}{|l|c|c|c|c|c|c|c|c|}
\hline Setor/Subsetores & RAIS 2003 & $\%$ & RAIS 2006 & $\%$ & RAIS 2007 & $\%$ & RAIS 2010 & $\%$ \\
\hline Comercializáveis & $\mathbf{5 0 9 0 1 9 2}$ & $\mathbf{2 0 , 2}$ & $\mathbf{6 0 9 4 2 0 0}$ & $\mathbf{2 0 , 6}$ & $\mathbf{6 6 3 1 9 1 2}$ & $\mathbf{2 0 , 5}$ & $\mathbf{7 3 2 4 4 9 1}$ & $\mathbf{1 9 , 3}$ \\
\hline Produtos Minerais não Metálicos & 262257 & 1,0 & 293062 & 0,9 & 319770 & 0,9 & 391148 & 1,0 \\
\hline Metalúrgica & 523153 & 2,0 & 626161 & 2,1 & 694242 & 2,1 & 772269 & 2,0 \\
\hline Mecânica & 308633 & 1,2 & 402997 & 1,3 & 471036 & 1,4 & 548754 & 1,4 \\
\hline Material elétrico e Comunicações & 184618 & 0,7 & 235995 & 0,8 & 262325 & 0,8 & 274257 & 0,7 \\
\hline Material de transporte & 329054 & 1,3 & 426239 & 1,4 & 485726 & 1,5 & 568719 & 1,5 \\
\hline Madeira e mobiliário & 398956 & 1,5 & 416487 & 1,4 & 431502 & 1,3 & 448119 & 1,1 \\
\hline Papel e gráfica & 301710 & 1,2 & 345860 & 1,1 & 361173 & 1,1 & 392670 & 1,0 \\
\hline Borracha, Fumo e Couros & 236053 & 0,9 & 273597 & 0,9 & 284919 & 0,8 & 301155 & 0,7 \\
\hline Química & 554486 & 2,2 & 650056 & 2,2 & 670576 & 2,0 & 875143 & 2,3 \\
\hline Têxtil & 702145 & 2,7 & 810043 & 2,7 & 885331 & 2,7 & 976984 & 2,5 \\
\hline Calçados & 266744 & 1,0 & 286578 & 0,9 & 303567 & 0,9 & 326432 & 0,8 \\
\hline Alimentos e Bebidas & 1022383 & 4,0 & 1327125 & 4,4 & 1461745 & 4,5 & 1448841 & 3,8 \\
\hline Não Comercializáveis & 13847874 & 54,9 & 16499178 & 55,7 & 18106714 & 56,1 & 22336273 & 58,9 \\
\hline Construção Civil & 1026660 & 4,0 & 1325962 & 4,4 & 1546440 & 4,7 & 2410931 & 6,3 \\
\hline Comércio Varejista & 4034851 & 16,0 & 4847200 & 16,3 & 5352599 & 16,5 & 6515125 & 17,1 \\
\hline Comércio Atacadista & 718620 & 2,8 & 916014 & 3,1 & 1039783 & 3,2 & 1282426 & 3,3 \\
\hline Instituições Financeiras & 518266 & 2,0 & 575026 & 1,9 & 610467 & 1,8 & 674960 & 1,7 \\
\hline Comércio e Administração de Imóveis & 2390631 & 9,4 & 2896686 & 9,7 & 3260035 & 10,1 & 4062484 & 10,7 \\
\hline Alojamento e Manutenção & 3259344 & 12,9 & 3578848 & 12,1 & 3907903 & 12,1 & 4510345 & 11,8 \\
\hline Médicos Odontológicos e Veterinários & 1004738 & 3,9 & 1149914 & 3,8 & 1201424 & 3,7 & 1443208 & 3,8 \\
\hline Ensino & 894764 & 3,5 & 1209528 & 4,0 & 1188063 & 3,6 & 1436794 & 3,7 \\
\hline Administração Pública & $\mathbf{6 2 5 1 8 9 8}$ & $\mathbf{2 4 , 8}$ & $\mathbf{6 9 8 7 0 4 7}$ & $\mathbf{2 3 , 6}$ & $\mathbf{7 5 1 8 5 0 4}$ & $\mathbf{2 3 , 3}$ & $\mathbf{8 2 6 3 2 1 4}$ & $\mathbf{2 1 , 7}$ \\
\hline Total & $\mathbf{2 5 1 8 9 9 6 4}$ & $\mathbf{1 0 0}$ & $\mathbf{2 9 5 8 0 4 2 5}$ & $\mathbf{1 0 0}$ & $\mathbf{3 2 2 5 7 1 3 0}$ & $\mathbf{1 0 0}$ & $\mathbf{3 7 9 2 3 9 7 8}$ & $\mathbf{1 0 0}$ \\
\hline
\end{tabular}

Fonte: Elaboração própria com base nos dados da RAIS/MTPS.

Uma dificuldade encontrada no presente estudo está relacionada à questão do registro dos vínculos públicos estaduais e federais, uma vez que a RAIS reportava para muitos municípios de médio porte localizados na fronteira do país pouco ou nenhum servidor federal ou estadual. Uma possível justificativa para isso é que grande parte dos vínculos federais e estaduais estão vinculados às capitais dos estados, tal que diferenças entre o número de servidores realmente vinculados ao município e aquele na RAIS constitui uma deficiência dessa base de dados. De fato, a existência de erros de medida nos registros nos municípios, apesar de ser atenuada ao se adotar a mesorregião como unidade geográfica, provavelmente passa para a variável mudança no emprego público, fortalecendo a suspeita de que essa variável é endógena no modelo (1). Por conta disso, espera-se que a estimação por variáveis instrumentais seja a preferível, pois torna as estimações dos betas no modelo (1) consistentes. 


\section{Resultados e Discussão}

A princípio, para estimar o parâmetro de impacto de mudanças no emprego público sobre o emprego privado local estimou-se o modelo econométrico da Equação (1), utilizando-se somente três variáveis de controle. No modelo original de Faggio e Overman (2014) foram utilizadas nove variáveis de controle no vetor $\mathrm{x}_{\mathrm{ip}}$. No entanto, não foi possível gerar as variáveis de controle para grau de instrução ${ }^{11}$ exatamente como em Faggio e Overman (2014), em razão do sistema de classificação da escolaridade no Reino Unido com sete níveis ser diferente do reportado na RAIS, que apresenta 11 níveis de escolaridade no Brasil.

Assim, a primeira das duas variáveis de controle no modelo foi a participação percentual de empregados qualificados (inicial), ou seja, no ano inicial de cada período, criada a partir do conceito de trabalhador qualificado de Moretti (2010), que considera qualificado o trabalhador com pelo menos uma graduação de nível superior, e não qualificado no caso do trabalhador com até o nível superior incompleto. A segunda variável de controle foi o logaritmo do total de empregados (inicial), pois é possível que o crescimento das mesorregiões e, assim, do emprego, seja correlacionado com o tamanho da cidade (Faggio e Overman 2014). Por fim, houve a inclusão da variável de controle "variação do PIB", em virtude da possível influência dessa variável na variação do emprego privado local.

O Quadro 5 apresenta as estatísticas descritivas das variáveis utilizadas nas estimações dos modelos. Observa-se, por exemplo, que nos dois períodos analisados, o emprego público apresentou forte variabilidade, o que retrata a heterogeneidade nas mudanças do emprego público (federal, estadual e municipal) entre as mesorregiões brasileiras. Em relação à variação do PIB por mesorregiões, verifica-se que o segundo período apresentou crescimento médio superior, possivelmente como resultado da política fiscal expansionista adotada.

${ }^{11}$ College degree and above; A-level; Apprenticeship; O-level, foundation diploma, other qualifications; e no qualifications (Faggio e Overman 2014, 94). 
Quadro 5 - Estatística descritivas das variáveis nos modelos

\begin{tabular}{|l|c|c|c|c|}
\hline \multirow{2}{*}{ Variável } & \multicolumn{2}{c|}{$2003-2006$} & \multicolumn{2}{c|}{$\mathbf{2 0 0 7 - 2 0 1 0}$} \\
\cline { 2 - 5 } & Média & $\begin{array}{c}\text { Desvio } \\
\text { Padrão }\end{array}$ & Média & $\begin{array}{c}\text { Desvio } \\
\text { Padrão }\end{array}$ \\
\hline $\begin{array}{l}\text { Mudança no emprego do setor privado (normalizada pelo emprego total } \\
\text { inicial) }\end{array}$ & 0,13 & 0,07 & 0,16 & 0,08 \\
\hline $\begin{array}{l}\text { Mudança no emprego do setor privado de comercializáveis (normalizada } \\
\text { pelo emprego total inicial) }\end{array}$ & 0,04 & 0,04 & 0,03 & 0,03 \\
\hline $\begin{array}{l}\text { Mudança no emprego do setor privado de não comercializáveis (normali- } \\
\text { zada pelo emprego total inicial) }\end{array}$ & 0,09 & 0,06 & 0,14 & 0,06 \\
\hline $\begin{array}{l}\text { Mudança no emprego do setor público (normalizada pelo emprego total } \\
\text { inicial) }\end{array}$ & 0,10 & 0,26 & 0,07 & 0,12 \\
\hline Participação de empregados qualificados (inicial) & 0,11 & 0,05 & 0,13 & 0,04 \\
\hline Log total empregados (inicial) & 11,1 & 1,4 & 11,4 & 1,32 \\
\hline Variação do PIB (mesorregiões) & 0,39 & 0,18 & 0,49 & 0,20 \\
\hline
\end{tabular}

Fonte: Elaboração própria com base nos dados da RAIS/MTPS.

A estimação de regressão com dados em painel é usualmente efetuada com base em três métodos distintos: o método do estimador MQO (Mínimos Quadrados Ordinários) com dados empilhados ou POLS (Pooled ordinary least square) e os métodos de estimação com efeitos fixos e com efeitos aleatórios. A escolha do estimador dentre os três dependerá de testes de especificação. Neste trabalho foram feitos os seguintes teste: Multiplicador de Lagrange de Breusch-Pagan ( $\mathrm{H}_{0}$ :POLS contra $\mathrm{H}_{1}$ :EA); F de Chow $\left(\mathrm{H}_{0}\right.$ :POLS contra $\left.\mathrm{H}_{1}: \mathrm{EF}\right)$ e Hausman $\left(\mathrm{H}_{0}\right.$ :EA contra $\left.\mathrm{H}_{1}: \mathrm{EF}\right)$.

O teste Multiplicador de Lagrange de Breusch-Pagan, aplicado após a estimação do modelo efeitos aleatórios, rejeita a hipótese de que o modelo é POLS em favor do modelo de efeitos aleatórios, já que $\chi^{2}=7,76$ ( $p$-value $=0,0027)$. Por meio do teste $\mathrm{F}$ de Chow, a hipótese de que não há efeitos fixos, ou seja, que são conjuntamente iguais a zero é rejeitada, $\mathrm{F}=1,96$ ( $p$ value $=0,0001$ ). Finalmente, os testes de Hausman (tradicional e robusto) levam à rejeição da hipótese nula de que o modelo é de efeitos aleatórios em favor do modelo de efeitos fixos, $\chi^{2}=22,26$ ( $p$-value $\left.=0,0005\right)$ e $\chi^{2}=21,314(p$-value $=0,0007$ ) respectivamente. Os resultados combinados desses testes apontam para utilização do método de dados em painel com efeitos fixos. 
Na Tabela 1 encontram-se as estimativas MQO agrupado (POLS), Efeitos Fixos (EF) e Efeitos Fixos com a variável instrumental (EF (VI)) do modelo econométrico (1) com erros-padrão robustos entre parênteses.

Tabela 1 - Estimativas MQO agrupado (POLS), Efeitos Fixos (EF) e Efeito Fixos realizadas para o modelo econométrico dado na equação (1) estimado com a VI mostrada na Equação (2) e com variável de interação entre a VI e dummy temporal para o Brasil

\begin{tabular}{|c|c|c|c|}
\hline & POLS & EF & $\mathrm{EF}(\mathrm{VI})$ \\
\hline Mudança no emprego do setor público & $\begin{array}{c}-0,1229^{\star * *} \\
(0,041)\end{array}$ & $\begin{array}{c}-0,1474^{\star \star *} \\
(0,036)\end{array}$ & $\begin{array}{c}-0,4664^{* *} \\
(0,214)\end{array}$ \\
\hline $\begin{array}{l}\text { Variável de interação (dummy de tempox mudança no } \\
\text { emprego do setor público) }\end{array}$ & $\begin{array}{c}0,2152^{\star * *} \\
(0,076)\end{array}$ & $\begin{array}{l}0,2870^{* *} \\
(0,137)\end{array}$ & $\begin{array}{l}1,2567^{\star \star *} \\
(0,311)\end{array}$ \\
\hline Participação de empregados qualificados (inicial) & $\begin{array}{l}0,0679 \\
(0,104)\end{array}$ & $\begin{array}{c}0,4433^{\star *} \\
(0,212)\end{array}$ & $\begin{array}{l}0,0470 \\
(0,285)\end{array}$ \\
\hline Log total empregados (inicial) & $\begin{array}{l}0,0026 \\
(0,005)\end{array}$ & $\begin{array}{l}-0,2302^{\star *} \\
-(0,101)\end{array}$ & $\begin{array}{c}-0,8352^{* * *} \\
(0,216)\end{array}$ \\
\hline Variação do PIB & $\begin{array}{c}0,0903^{\star * *} \\
(0,020)\end{array}$ & $\begin{array}{c}-0,0728^{\star \star *} \\
(0,026)\end{array}$ & $\begin{array}{c}-0,1176^{* *} \\
(0,054)\end{array}$ \\
\hline Dummy de tempo (efeitos fixos de tempo) & $\begin{array}{l}0,0031 \\
(0,009)\end{array}$ & $\begin{array}{c}0,0600^{\star *} \\
(0,023)\end{array}$ & $\begin{array}{c}0,1704^{* * *} \\
(0,046)\end{array}$ \\
\hline Constante & $\begin{array}{l}0,0705 \\
(0,062)\end{array}$ & $\begin{array}{c}2,6333^{\star *} \\
(1,133)\end{array}$ & (a) \\
\hline Número de observações & 274 & 274 & 274 \\
\hline \multicolumn{4}{|c|}{ Primeiro Estágio } \\
\hline Estatística $\mathrm{F}^{(\mathrm{b})}$ & & & $3,5^{\star \star}$ \\
\hline
\end{tabular}

Notas: Erros-padrão robustos agrupados por mesorregião (clustered standard errors); ${ }^{* * *} \mathrm{p}<0,01$, ${ }^{* *} \mathrm{p}<0,05,{ }^{*} \mathrm{p}<0,1$; (a) a constante não é reportada na estimação pelo software Stata 13 , comando xtivreg2, fe cluster(mesorregião) robust; (b) teste da hipótese de instrumentos fracos contra a hipótese de instrumentos fortes.

Fonte: Elaboração própria.

As estimativas POLS e EF reportadas na Tabela 1 servem somente para demonstrar, por comparação, a robustez dos resultados obtidos quanto ao sinal dos efeitos, pois as estimativas de fato relevantes são as do modelo EF (VI), uma vez que pelo teste F se conclui que o instrumento utilizado é forte ou relevante. Assim, há um efeito eliminador e significativo da 
mudança no emprego público no emprego no mercado de trabalho privado local no primeiro período do governo do presidente Lula (2003-2006), segundo o qual, para cada cem empregos públicos criados, estima-se que são eliminados aproximadamente quarenta e seis empregos no setor privado no Brasil. Já no segundo período do governo do presidente Lula (20072010) há um efeito multiplicador, segundo o qual estima-se uma geração de setenta e nove empregos no setor privado (pois ) para cada cem empregos públicos criados. Em suma, os resultados indicam que o impacto do aumento no emprego público sobre o emprego privado local é eliminador no primeiro governo Lula e multiplicador no segundo governo Lula, refutando-se a hipótese de que esse parâmetro de impacto se manteve igual nos dois governos do presidente Lula.

\subsection{Resultados do Modelo para o Setor de Comercializáveis da Economia}

Investiga-se nesta subseção a contribuição do emprego público sobre o mercado de trabalho privado local no setor de comercializáveis (indústria). Em relação aos testes de especificação, o Multiplicador de Lagrange de Breusch-Pagan, rejeita hipótese de que o modelo é POLS em favor do modelo de efeitos aleatórios, $\chi^{2}=13,37$ ( $p$-value $\left.=0,0001\right)$. Por meio do teste $\mathrm{F}$ de Chow, a hipótese de que não há efeitos fixos é rejeitada, $\mathrm{F}=$ 2,37 ( $p$-value $=0,000)$. Finalmente, os testes de Hausman (tradicional e robusto) levam à rejeição da hipótese nula de que o modelo é de efeitos aleatórios em favor do modelo de efeitos fixos, $\chi^{2}=19,02$ ( $p$-value $=$ 0,0019 ) e $\chi^{2}=22,015$ ( $p$-value $=0,0005$ ) respectivamente. Isso posto, os resultados combinados desses testes também apontam para utilização do método de dados em painel com efeitos fixos.

A Tabela 2 apresenta as estimativas MQO agrupado (POLS), Efeitos Fixos (EF) e Efeito Fixos com a variável instrumental (EF (VI)) do modelo econométrico (1) com erros-padrão robustos entre parênteses, obtidas com dados do setor de comercializáveis. 
Tabela 2 - Estimativas MQO agrupado (POLS), Efeitos Fixos (EF) e Efeito Fixos realizadas para o modelo econométrico dado na equação (1) estimado com a VI mostrada na Equação (2) e com variável de interação entre a VI e dummy temporal para o setor de comercializáveis do Brasil

\begin{tabular}{|c|c|c|c|}
\hline & POLS & EF & $\mathrm{EF}(\mathrm{VI})$ \\
\hline Mudança no emprego do setor público & $\begin{array}{l}-0,0254 \\
(0,016)\end{array}$ & $\begin{array}{r}-0,0280^{*} \\
(0,014)\end{array}$ & $\begin{array}{c}-0,1492^{\star *} \\
(0,069)\end{array}$ \\
\hline $\begin{array}{l}\text { Variável de interação (dummy de tempox mudança no } \\
\text { emprego do setor público) }\end{array}$ & $\begin{array}{l}0,0382 \\
(0,044)\end{array}$ & $\begin{array}{l}0,1551^{* * *} \\
(0,050)\end{array}$ & $\begin{array}{c}0,3926^{* * *} \\
(0,112)\end{array}$ \\
\hline Participação de empregados qualificados (inicial) & $\begin{array}{l}-0,0676 \\
(0,046)\end{array}$ & $\begin{array}{c}0,1371^{* *} \\
(0,068)\end{array}$ & $\begin{array}{l}0,0182 \\
(0,125)\end{array}$ \\
\hline Log total empregados (inicial) & $\begin{array}{l}0,0037 \\
(0,002)\end{array}$ & $\begin{array}{c}-0,1043^{* *} \\
(0,042)\end{array}$ & $\begin{array}{c}-0.2689^{\star * *} \\
(0,098)\end{array}$ \\
\hline Variação do PIB & $\begin{array}{l}0,0000 \\
(0,011)\end{array}$ & $\begin{array}{l}-0,0044 \\
(0,018)\end{array}$ & $\begin{array}{c}0.0114^{* * *} \\
(0,020)\end{array}$ \\
\hline Dummy de tempo (efeitos fixos de tempo) & $\begin{array}{c}-0,0182^{* * *} \\
(0,004)\end{array}$ & $\begin{array}{l}0,0012 \\
(0,010)\end{array}$ & $\begin{array}{l}0,0321^{*} \\
(0,022)\end{array}$ \\
\hline Constante & $\begin{array}{l}0,0093 \\
(0,029)\end{array}$ & $\begin{array}{l}1,1935^{*} \\
(0,479)\end{array}$ & (a) \\
\hline Número de observações & 274 & 274 & 274 \\
\hline \multicolumn{4}{|c|}{ Primeiro Estágio } \\
\hline Estatística $\mathrm{F}^{(\mathrm{b})}$ & & & $3,5^{\star \star}$ \\
\hline
\end{tabular}

Notas: Erros-padrão robustos agrupados por mesorregião (clustered standard errors); $* * * \mathrm{p}<0,01$, ${ }^{* *} \mathrm{p}<0,05,{ }^{*} \mathrm{p}<0,1$; (a) a constante não é reportada na estimação pelo software Stata 13 (comando xtivreg2, fe cluster(mesorregião) robust); (b) teste da hipótese de instrumentos fracos contra a hipótese de instrumentos fortes.

Fonte: Elaboração própria.

As estimativas POLS e EF reportadas na Tabela 2 servem apenas como referência para demonstrar a robustez dos resultados, pois as estimativas de fato relevantes são as do modelo EF (VI), uma vez que pelo teste F se conclui que o instrumento utilizado é forte ou relevante. As estimativas EF (VI) indicam um efeito eliminador de quatorze postos de trabalho no setor de comercializáveis para cada cem empregos gerados no setor público e estão em linha com a estrutura conceitual de Faggio e Overman (2014). Já no segundo período, há um efeito multiplicador da ordem de vinte e 
cinco empregos gerados no setor de comercializáveis para cada cem empregos criados no setor público. Em suma, o impacto do aumento no emprego público sobre o emprego no setor comercializáveis local é eliminador no primeiro governo Lula, mas multiplicador no segundo governo Lula.

Ainda que para o primeiro período os resultados encontrados corroborem as implicações do modelo conceitual, a existência de um efeito multiplicador no setor de comercializáveis no segundo governo Lula vai de encontro à predição do modelo conceitual. Diante desse resultado, supõe-se que existiram políticas de foco local de aumento da competitividade setorial que mais que compensaram a redução da competitividade do setor local de bens comercializáveis devido ao aumento dos salários, do custo de habitação e do preço de bens e serviços não comercializáveis localmente. Por exemplo, o estabelecimento da política de conteúdo local no setor de petróleo e gás trouxe estímulos a diversas cadeias industriais devido ao grande volume de investimento público e privado em setores de infraestrutura por meio do plano de aceleração do crescimento (PAC).

\subsection{Resultados do Modelo (1) para o Setor de Não Comercializáveis da Economia}

Finalmente, nesta subseção investiga-se o impacto da mudança no emprego público sobre o mercado de trabalho privado local para o setor de bens e serviços não comercializáveis. No tocante aos testes de especificação, o Multiplicador de Lagrange de Breusch-Pagan, rejeita a hipótese de que o modelo é POLS em favor do modelo de efeitos aleatórios, $\chi^{2}=9,64$ ( $p$ value $=0,0009)$. Por meio do teste $\mathrm{F}$ de Chow, a hipótese de que não há efeitos fixos é rejeitada, $\mathrm{F}=2,06$ ( $p$-value $=0,000$ ). Finalmente, os testes de Hausman (tradicional e robusto) levam à rejeição da hipótese nula de que o modelo é de efeitos aleatórios em favor do modelo de efeitos fixos, $\chi^{2}=22,10(p$-value $=0,0005)$ e $\chi^{2}=23,71$ ( $p$-value $\left.=0,0002\right)$ respectivamente. Os resultados combinados desses testes também apontam para utilização do método de dados em painel com efeitos fixos.

A Tabela 3 apresenta as estimativas MQO agrupado (POLS), Efeitos Fixos (EF) e Efeito Fixos com a variável instrumental (EF (VI)) do modelo econométrico (1) com erros-padrão robustos entre parênteses, obtidas com dados apenas de bens e serviços não comercializáveis. 
Tabela 3 - Estimativas MQO agrupado (POLS), Efeitos Fixos (EF) e Efeito Fixos realizadas para o modelo econométrico dado na equação (1) estimado com a VI mostrada na Equação (2) e com variável de interação entre a VI e dummy temporal para o setor de não comercializáveis do Brasil

\begin{tabular}{|c|c|c|c|}
\hline & POLS & EF & $\mathrm{EF}(\mathrm{VI})$ \\
\hline Mudança no emprego do setor público & $\begin{array}{c}-0,0974^{* * *} \\
(0,027)\end{array}$ & $\begin{array}{c}-0,1193^{* * \star} \\
(0,026)\end{array}$ & $\begin{array}{c}-0,3171^{*} \\
(0,164)\end{array}$ \\
\hline $\begin{array}{l}\text { Variável de interação (dummy de tempox mudança no } \\
\text { emprego do setor público) }\end{array}$ & $\begin{array}{c}0,1770^{\star \star *} \\
(0,042)\end{array}$ & $\begin{array}{l}0,1318 \\
(0,104)\end{array}$ & $\begin{array}{c}0,8641^{* * *} \\
(0,243)\end{array}$ \\
\hline Participação de empregados qualificados (inicial) & $\begin{array}{l}0,1356 \\
(0,088)\end{array}$ & $\begin{array}{l}0,3062^{*} \\
(0,168)\end{array}$ & $\begin{array}{l}0,0287 \\
(0,183)\end{array}$ \\
\hline Log total empregados (inicial) & $\begin{array}{r}-0,0011 \\
(0,004)\end{array}$ & $\begin{array}{l}-0,1258 \\
(0,080)\end{array}$ & $\begin{array}{c}-0,566^{\star \star \star} \\
(0,150)\end{array}$ \\
\hline Variação do PIB & $\begin{array}{c}0,0902^{* * *} \\
(0,021)\end{array}$ & $\begin{array}{c}0,0772^{* * *} \\
(0,025)\end{array}$ & $\begin{array}{l}0,1061^{* *} \\
(0,042)\end{array}$ \\
\hline Dummy de tempo (efeitos fixos de tempo) & $\begin{array}{c}0,0214^{\star \star *} \\
(0,007)\end{array}$ & $\begin{array}{c}0,0587^{\star \star \star} \\
(0,019)\end{array}$ & $\begin{array}{c}0,138^{\star \star *} \\
(0,030)\end{array}$ \\
\hline Constante & $\begin{array}{l}0,0611 \\
(0,050)\end{array}$ & $\begin{array}{l}1,4398 \\
(0,898)\end{array}$ & (a) \\
\hline Número de observações & 274 & 274 & 274 \\
\hline \multicolumn{4}{|c|}{ Primeiro Estágio } \\
\hline Estatística $\mathrm{F}^{(\mathrm{b})}$ & & & $3,5^{\star \star}$ \\
\hline
\end{tabular}

Notas: Erros-padrão robustos agrupados por mesorregião (clustered standard erros); ${ }^{* * *} \mathrm{p}<0,01$, ${ }^{* *} \mathrm{p}<0,05,{ }^{*} \mathrm{p}<0,1$; (a) a constante não é reportada na estimação pelo software Stata 13 (comando xtivreg2, fe cluster(mesorregião) robust); (b) teste da hipótese de instrumentos fracos contra a hipótese de instrumentos fortes.

Fonte: Elaboração própria.

As estimativas POLS e EF reportadas na Tabela 3 mostram que os resultados são robustos. As estimativas referentes ao modelo EF (VI) indicam um efeito eliminador da ordem de trinta e um postos de trabalho no setor de não comercializáveis para cada cem empregos gerados no setor público. Para o segundo período, há um efeito multiplicador da ordem de cinquenta e cinco empregos gerados no setor de não comercializáveis para cada cem empregos públicos criados. Em suma, o impacto do aumento no emprego público sobre o emprego no setor de não comercializáveis local é eliminador no primeiro governo Lula e multiplicador no segundo governo Lula. 


\subsection{Resultados do Modelo (1) com Especificação Espacial EF-SLX}

As unidades espaciais mesorregiões brasileiras são compostas pelos municípios brasileiros que têm cada um, o seu prefeito. Com isso, tona-se improvável existir comportamento estratégico das mesorregiões diante das dificuldades inerentes à coordenação de vários prefeitos e, assim, improvável haver correlação espacial. Com base nisso, descartamos por completo a possibilidade do modelo Spatial Autoregressive (SAR). De fato, segundo Gibbons e Overman (2012), há situações que exigem o abandono completo do modelo SAR, sugerindo que o caminho a seguir para se captar possíveis efeitos de vizinhança é a estimação de modelos Spatial Lag of X (SLX).

Consideramos que se houver correlação espacial deve ser devido ao efeito de equilíbrio geral espacial desencadeado por mudanças no emprego público. Por exemplo, um aumento do emprego público em uma mesorregião aumenta os salários e o nível de emprego nesta, o que estimula a migração dos vizinhos para lá. Com a migração, há uma redução na oferta de trabalho nos vizinhos e, como consequência, uma redução no nível de emprego e aumento nos salários nestes. Ou seja, se há efeito espacial, conjecturamos que um aumento no emprego público em uma mesorregião reduz o nível de emprego nas mesorregiões vizinhas, tal que a omissão do emprego público das mesorregiões vizinhas sobre-estimaria os efeitos multiplicadores e subestimaria os efeitos eliminadores (crowding out).

Para investigar se há efeito espacial, estimamos um modelo Efeitos Fixos Spatial Lag of X (EF-SLX). Para tanto, acrescentamos à especificação original do modelo na Equação (1) um termo formado pela multiplicação da matriz de pesos espaciais W (de dimensão $274 \times 274$ ) pela matriz de dimensão $274 \times 2$ dos dados das variáveis mudança no emprego do setor público e a interação (dummy de tempo $\times$ mudança no emprego do setor público), que é também multiplicada pelo vetor de parâmetros teta de dimensão $2 \times 1$. Vide detalhes sobre o modelo EF-SLX em Belotti et al. (2017). Em seguida, criamos, com o comando spmat do Stata (Drukker 2013), uma matriz W contígua ${ }^{12}$ de ponderação ou pesos espaciais, utilizando os centroides das mesorregiões obtidos com o shapefile das mesorregiões brasileiras no software IPEAGEO (Carvalho et al. 2011). Finalmente, estimamos por máxima verossimilhança um modelo Efeitos Fixos Spatial Lag of X (EF-

\footnotetext{
${ }^{12}$ Em uma matriz contígua, unidades espaciais contíguas recebem peso um, enquanto unidades espaciais não contíguas, o peso zero. As unidades espaciais contíguas são chamadas de vizinhos (Drukker et al. 2013).
} 
SLX) com o comando xsmle do Stata (Belotti et al., 2017). A Tabela 4 apresenta os resultados dos testes de Wald da hipótese de que os efeitos das defasagens espaciais da mudança no emprego do setor público e da interação (dummy de tempo× mudança no emprego do setor público) são conjuntamente zero.

Tabela 4 - Resultados dos testes de Wald da hipótese de que os efeitos das defasagens espaciais da mudança no emprego do setor público e da interação (dummy de tempox mudança no emprego do setor público) são conjuntamente zero com base nas estimativas de Máxima Verossimilhança do modelo EF-SLX

\begin{tabular}{l|c|c}
\hline & $\chi 2(2)$ & p-valor \\
\hline Para o Brasil & 0,02 & 0,9965 \\
\hline Para o setor de comercializáveis do Brasil & 0,51 & 0,7739 \\
\hline Para o setor de não comercializáveis do Brasil & 0,11 & 0,9484 \\
\hline
\end{tabular}

Fonte: Elaboração própria.

Com base nos resultados na Tabela 4, concluímos que não há efeito espacial da mudança no emprego do setor público na economia do Brasil como um todo, e nem no setor de comercializáveis e no setor de não comercializáveis da economia brasileira, o que corrobora os resultados e conclusões apresentados nas seções anteriores do presente trabalho.

\section{Conclusões}

A partir da agregação dos 5.658 de municípios brasileiros em 137 mesorregiões, o presente artigo estimou o impacto da mudança no emprego público sobre o emprego privado no período de 2003 a 2010 no Brasil. Ainda, investigou-se se a mudança no emprego público afetou a composição setorial do emprego no curto prazo, como propõem Faggio e Overman (2014), estimando o parâmetro de impacto nos setores de não comercializáveis (construção e serviços) e de bens comercializáveis (indústria).

A recente valorização das carreiras públicas e o forte apelo político que permeia as decisões sobre a contratação de servidores públicos no Brasil foram os elementos motivadores para a realização do presente estudo. Já a 
metodologia de estimação com base em variáveis instrumentais de Faggio e Overman (2014) serviu como base. No entanto, o presente trabalho inova ao utilizar dados em painel e uma especificação do modelo que permite ao parâmetro de impacto variar entre os dois governos do presidente Lula.

Os resultados indicaram que o parâmetro de impacto da mudança no emprego público sobre o emprego privado no período de 2003 a 2010 sofreu alterações entre os governos Lula. De fato, os resultados obtidos para economia brasileira como um todo e para os setores de comercializáveis e não comercializáveis indicaram que a mudança da política fiscal de contracionista para expansionista alterou o parâmetro da economia que rege o impacto da mudança no emprego público sobre o emprego privado no Brasil, e que isso afetou a composição setorial do emprego no curto prazo no Brasil. Em um cenário de política fiscal contracionista, como foi o do primeiro governo Lula (2003 a 2006), o impacto foi eliminador, com o emprego público substituindo o emprego privado, enquanto que em um cenário com política fiscal expansionista, como foi o do segundo governo Lula (2007 a 2010), esse efeito foi multiplicador, com o emprego público complementando o emprego privado.

No tocante à magnitude dos multiplicadores encontrados em relação ao estudo de Faggio e Overman (2014), destaca-se a disparidade do efeito gerado pela contratação de empregos públicos no setor privado local. No período de 1999 a 2007, a cada cem empregos públicos gerados no Reino Unido, houve a eliminação do mesmo número de empregos no setor privado. Para o Brasil, no intervalo de oito anos (2003-2010), verificou-se que o efeito estimado para cada cem empregos públicos gerados foi, no período de 2003 a 2006, a eliminação de quarenta e seis empregos no setor privado; já no período de 2007 a 2010, o efeito estimado foi a criação de setenta e nove empregos no setor privado. Diferenças entre as experiências de desenvolvimento entre os países e a influência de diferentes características regionais são possíveis explicações para a desproporção nos resultados. Em termos de apoio à tomada de decisão de política pública, os resultados encontrados mostram que se a política fiscal vigente é contracionista e há necessidade de aumentar o emprego total da economia, o governo tem com instrumento a não reposição de servidores. Caso a política fiscal vigente seja expansionista e haja necessidade de aumento do emprego total da economia, o governo tem com instrumento a contratação de novos servidores. Todavia, há que se considerar o custo de oportunidade dessa política ante 


\section{outras políticas de fomento do mercado de trabalho e os possíveis impactos da expansão do emprego público no equilíbrio das finanças públicas.}

\section{Para pesquisas futuras, sugere-se estudar o efeito da variação do emprego público nos salários no setor privado, inclusive, aprofundando a investiga- ção com o uso de ferramentas de econometria espacial.}

\section{Referências}

Algan, Yann, Pierre Cahuc, and André Zylberberg. 2002. "Public employment and labour market performance, Economic Policy”. 17 (34): 7-66. doi.org/10.1111/1468-0327.00083

Baltagi, Badi H. 2005. Econometric Analysis of Panel Data. Nova York: John Wiley \& Sons Ltd.

Barbosa, Ana Luiza Neves de Holanda Barbosa, and Fernando de Holanda Barbosa Filho. 2012. "Diferencial de salários e determinantes na escolha de trabalho entre os setores público e privado no Brasil". Texto para Discussão 1713. Instituto de Pesquisas Econômicas Avançadas - IPEA.

Belotti, Federico, Gordon Hughes and Andrea Pianto Mortari. 2017. "Spatial panel-data models using Stata". Stata Journal 17 (1): 139-180.

Blasio, Guido de, and Carlo Menon. 2011. "Local effects of manufacturing employment growth in Italy". Giornale degli Economisti e Annali di Economia 70 (3): 101-112.

Boeri, Tito, and Pietro Garibaldi. 2006. "Are Labour Markets in the New Member States Sufficiently Flexible for EMU?” Journal of Banking \& Finance 30 (5): 1393-1407. doi.org/10.1016/j.jbankfin.2005.07.005

Boeri, Tito, Giuseppe Nicoletti and Stefano Scarpetta. 1999. "Regulation and Labour Market Performance". IGIER Working Paper n. 158: 1-48.

Card, David. 2007. "How immigration affects U.S. Cities". Acessed march 11, 2016. http://www.cream-migration. org/publ_uploads/CDP_11_07.pdf.

Carvalho, Alexandre Xavier Ywata et al. 2011. “IPEAGEO”. Boletim Regional e Urbano do IPEA n. 5: 155-166.

Dinc, Mustafa. 2002. "Regional and Local Economic Analysis Tools". World Bank Institute, The World Bank.

Drukker, David M. et al. 2013. "Creating and managing spatial-weighting matrices with the spmat command". Stata Journal 13 (2): 242-286.

Dunn, Edgar. S. 1960. “A Statistical and Analytical Technique for Regional Analysis”. Papers of the Regional Science Association 6: 97-112. doi: 10.1111/j.1435-5597.1960.tb01705.x

Dyrstad, Eirik Handegård. 2014. "Local Employment Multipliers in Norway: A Comparative Study of Norway, Sweden and the United States". Master Thesis, University of Oslo.

Edin, Per-Anders and Bertil Holmlund. 1997. "Sectoral structural change and the state of the labour market in Sweden”. In Siebert H. (Ed.) Structural Change and Labour Market Flexibility, Mohr Siebeck, 89 -121.

Faggio, Giulia and Henry Overman. 2014. "The effect of public sector employment on local labour markets". Journal of Urban Economics 79: 91-107. doi.org/10.1016/j.jue.2013.05.2002.

Gibbons, Stefen and Henry G. Overman. 2012. "Mostly pointless spatial econometrics?” Journal of Regional Science, 52: 172-191. doi:10.1111/j.1467-9787.2012.00760.x

Gujarati, Damodaran N. 2004. Basic Econometrics. USA: Mcgraw-Hill. 
Holmlund, Bertil. 1997. "Macroeconomic Implications of a Cash Limits in the Public Sector". Economica 64: 49-62. doi: 10.1111/1468-0335.00063.

Jofre-Monseny, Jordi, José J. Silva and Javier Vazquez-Grenno. 2014. “Local multipliers of public employment: Long-run evidence from the late development of the Spanish public sector." Acessed January 05, 2016. http:// www.ieb.ub.edu/files/PapersWSUE2014/Jofre.pdf.

Mayor Fernández, M., A.J. López Menéndez, and R. Pérez Suárez. 2005. "Escenarios de empleo regional. Una propuesta basada en análisis shift-share". Estudios de Economía Aplicada 23 (3): 863-887.

Macedo, Guilherme Macedo and Leonardo M. Monasterio. 2014. "Multiplicador Local do Emprego: Mesorregiões Brasileiras (2000 - 2010)". Texto para Discussão 1994. Instituto de Pesquisas Econômicas Avançadas - IPEA.

Marconi, Nelson and Marcos Rocha. 2011. "Desindustrialização precoce e sobrevalorização da taxa de câmbio". Texto para Discussão 1.681. Instituto de Pesquisas Econômicas Avançadas - IPEA.

Máté, Domicián. 2010. "A theoretical and growth accounting approach of jobless growth". Periodica Oeconomica, 67-76.

Moretti, Enrico. 2010. "Local Multiplies". The American Economic Review, 100 (2): 373-377.

Moretti, Enrico and Per Thulin. 2012. "Local Multiplies and Human Capital in the US and Sweden. Research Institute of Industrial Economics. IFN Working Paper n. 914.

Nunes, Alcina and Elisa Barros. 2012. "Evolução do desemprego regional em Portugal entre 2004 e 2009: aplicação da análise shift-share". Egitania Sciencia, 10: 19-40.

OECD. 2015. "Employment in the public sector", in Government at a Glance 2015, OECD Publishing, Paris. doi.org/10.1787/gov_glance-2015-22-en.

Senftleben-König, Charlotte. 2014. "Public Sector Employment and Local Multipliers". Working Paper Series 2014-10.

Souza, Pedro H. G. F. and Marcelo Medeiros. 2013. "Diferencial salarial público-privado e desigualdade de renda per capita no Brasil". Estudos Econômicos, 43(1): 05-28.

Stepanyan, Ara and Lamin Leigh. 2015. "Fiscal policy implications for labor market outcomes in middle income countries", IMF Working Paper, N. 15/17.

Wooldridge, J. M. 2002. Econometric analysis of cross section and panel data. Cambridge, MA: MIT Press. 


\section{ANEXO A}

\section{Quadro Al - Mesorregiões brasileiras e a unidade da federação a qual pertence em parênteses}

\begin{tabular}{|c|c|c|}
\hline 1 - Vale do Juruá (AC) & 48 - Leste de Mato Grosso do Sul (MS) & 95- Sul Fluminense (RJ) \\
\hline $2-$ Vale do Acre (AC) & 49 - Sudoeste de Mato Grosso do Sul (MS) & 96 - Metropolitana do Rio de Janeiro (RJ) \\
\hline 3 - Sertão Alagoano (AL) & 50 - Noroeste de Minas (MG) & 97 - Oeste Potiguar (RN) \\
\hline 4 - Agreste Alagoano (AL) & 51 - Norte de Minas (MG) & 98 - Central Potiguar (RN) \\
\hline 5 - Leste Alagoano $(\mathrm{AL})$ & 52 - Jequitinhonha (MG) & 99 - Agreste Potiguar (RN) \\
\hline 6 - Norte Amapá (AP) & 53 - Vale do Mucuri (MG) & 100 - Leste Potiguar (RN) \\
\hline 7 - Sul do Amapá (AP) & 54 - Triângulo Mineiro/Alto Paranaíba (MG) & 101 - Noroeste Rio-grandense (RS) \\
\hline 8 - Norte Amazonense (AM) & 55 - Central Mineira (MG) & 102 - Nordeste Rio-grandense (RS) \\
\hline 9 - Sudoeste Amazonense (AM) & 56- Metropolitana de Belo Horizonte (MG) & 103 - Centro Ocidental Rio-grandense (RS) \\
\hline 10- Centro Amazonense (AM) & 57 - Vale do Rio Doce (MG) & 104 - Centro Oriental Rio-grandense (RS) \\
\hline 11- Sul Amazonense (AM) & 58 - Oeste de Minas (MG) & 105 - Metropolitana de Porto Alegre (RS) \\
\hline 12- Extremo Oeste Baiano (BA) & 59 - Sul/Sudoeste de Minas (MG) & 106 - Sudoeste Rio-grandense (RS) \\
\hline 13- Vale São-Franciscano da Bahia (BA) & 60 - Campo das Vertentes (MG) & 107 - Sudeste Rio-grandense (RS) \\
\hline 14- Centro Norte Baiano (BA) & 61 - Zona da Mata (MG) & 108 - Madeira-Guaporé (RO) \\
\hline 15 - Nordeste Baiano (BA) & 62 - Baixo Amazonas (PA) & 109 - Leste Rondoniense (RO) \\
\hline 16 -Metropolitana de Salvador (BA) & 63 - Marajó (PA) & 110 - Norte de Roraima (RR) \\
\hline 17 -Centro Sul Baiano (BA) & 64 - Metropolitana de Belém (PA) & 111 - Sul de Roraima (RR) \\
\hline 18 - Sul Baiano (BA) & 65 - Nordeste Paraense (PA) & 112 - Oeste Catarinense (SC) \\
\hline 19 - Noroeste Cearense (CE) & 66 - Sudoeste Paraense (PA) & 113 - Norte Catarinense (SC) \\
\hline 20 - Norte Cearense (CE) & 67 - Sudeste Paraense (PA) & 114 - Serrana (SC) \\
\hline 21- Metropolitana de Fortaleza (CE) & 68 - Sertão Paraibano (PB) & 115 - Vale do Itajaí (SC) \\
\hline 22- Sertões Cearenses (CE) & 69 - Borborema (PB) & 116 - Grande Florianópolis (SC) \\
\hline 23- Jaguaribe (CE) & 70 - Agreste Paraibano (PB) & 117 - Sul Catarinense (SC) \\
\hline 24 -Centro-Sul Cearense (CE) & 71 - Mata Paraibana (PB) & 118 - São José do Rio Preto (SP) \\
\hline 25 - Sul Cearense (CE) & 72 - Noroeste Paranaense (PR) & 119 - Ribeirão Preto (SP) \\
\hline 26 - Brasília (DF) & 73 - Centro Ocidental Paranaense (PR) & 120 - Araçatuba (SP) \\
\hline 27 - Noroeste Espírito-santense (ES) & 74 - Norte Central Paranaense (PR) & 121 - Bauru (SP) \\
\hline 28 - Litoral Norte Espírito-santense (ES) & 75 - Norte Pioneiro Paranaense (PR) & 122 - Araraquara (SP) \\
\hline 29 - Central Espírito-Santense (ES) & 76 - Centro Oriental Paranaense (PR) & 123 - Piracicaba (SP) \\
\hline 30 - Sul Espírito-santense (ES) & 77 - Oeste Paranaense (PR) & 124 - Campinas (SP) \\
\hline 31 - Noroeste Goiano (GO) & 78- Sudoeste Paranaense (PR) & 125 - Presidente Prudente (SP) \\
\hline 32 - Norte Goiano (GO) & 79- Centro-Sul Paranaense (PR) & 126 - Marília (SP) \\
\hline 33 - Centro Goiano (GO) & 80- Sudeste Paranaense (PR) & $127-$ Assis (SP) \\
\hline 34 - Leste Goiano (GO) & 81- Metropolitana de Curitiba (PR) & 128 - Itapetininga (SP) \\
\hline 35 - Sul Goiano (GO) & 82 - Sertão Pernambucano (PE) & 129 - Macro Metropolitana Paulista (SP) \\
\hline 36 - Norte Maranhense (MA) & 83 - São Francisco Pernambucano (PE) & 130 - Vale do Paraíba Paulista (SP) \\
\hline 37 - Oeste Maranhense (MA) & 84 - Agreste Pernambucano (PE) & 131 - Litoral Sul Paulista (SP) \\
\hline 38 - Centro Maranhense (MA) & 85 - Mata Pernambucana (PE) & 132 - Metropolitana de São Paulo (SP) \\
\hline 39 - Leste Maranhense (MA) & 86 - Metropolitana de Recife (PE) & 133 -Sertão Sergipano (SE) \\
\hline 40 - Sul Maranhense (MA) & 87 - Norte Piauiense (PI) & 134 - Agreste Sergipano (SE) \\
\hline 41 - Norte Mato-grossense (MT) & 88 - Centro-Norte Piauiense (PI) & 135 -Leste Sergipano (SE) \\
\hline 42 - Nordeste Mato-grossense (MT) & 89 - Sudoeste Piauiense (PI) & 136 - Ocidental do Tocantins (TO) \\
\hline 43 - Sudoeste Mato-grossense (MT) & 90 - Sudeste Piauiense (PI) & 137 - Oriental do Tocantins (TO) \\
\hline 44 - Centro-Sul Mato-grossense (MT) & 91 - Noroeste Fluminense (RJ) & \\
\hline 45 - Sudeste Mato-grossense (MT) & 92 - Norte Fluminense (RJ) & \\
\hline 46 - Pantanais Sul Mato-grossense (MS) & 93 - Centro Fluminense (RJ) & \\
\hline 47 - Centro Norte de Mato Grosso do Sul (MS) & 94 - Baixadas (RJ) & \\
\hline
\end{tabular}

Fonte: IBGE.

Estud. Econ., São Paulo, vol.48 n.1, p. 77-106, jan.-mar. 2018 